\title{
Right ventricular obstruction due to anomalous muscle bands
}

\author{
Raman Patel and Roy Astley \\ From The Children's Hospital, Ladywood Middleway, Birmingham
}

Two cases of anomalous muscle bands causing right ventricular obstruction have been described. Clinical, electrocardiographic, and cardiac catheterization findings suggest a common pattern, probably a separate embryological entity from a low infundibular obstruction. Pitfalls in diagnosis have been discussed.

Subinfundibular obstruction of the right ventricle is a rare congenital cardiac abnormality which has been well described mainly over the past decade. The right ventricle is divided into a proximal high pressure chamber and a distal low pressure chamber. The obstruction is caused by an anomalous muscle bundle or multiple muscle bundles of either abnormal or normal bulbar muscle. Clinical recognition of the defect may be difficult, as it is frequently associated with ventricular septal defects. In I5 cases reported by Fisher et al. (197I) there was an associated ventricular septal defect in 14 . Coexisting pulmonary valve stenosis, pulmonary atresia, and persistent ductus arteriosus have all been previously reported to occur infrequently (Gale, Heimann, and Barlow, 1969).

We report a further two cases without associated ventricular septal defects.

\section{Case reports}

Case I (age 15 years)

She was first seen when 5 months old because of a systolic cardiac murmur heard on a routine examination. She remained well apart from frequent respiratory infections during infancy but was noticed to have idiopathic sexual precocity when 6 years old and started to get breathless after exertion at the age of 13 years. On examination, she was well built. There was no dyspnoea or cyanosis at rest. A thrill was felt in the left lower parasternal region and a loud long systolic murmur was audible in the 3 rd to 4 th left intercostal spaces. The second sound was split with normal respiratory variation but the pulmonary component of the second sound was attenuated.

An electrocardiogram showed a frontal QRS axis of $+45^{\circ}$. The QRS complex in lead aVR was entirely negative and $S$ waves were absent in leads V5 to V6.

Received 12 March 1973.
A chest radiograph did not show any cardiomegaly and the lung vascularity was considered to be normal (Fig. I). Cardiac catheterization showed a systolic pressure gradient at subinfundibular level - the pressure in the proximal inflow chamber being $110 / 8 \mathrm{mmHg}$ and $40 / 4 \mathrm{mmHg}$ in the distal chamber. There was a further systolic pressure gradient of $28 \mathrm{mmHg}$ across the pulmonary valve. A selective angiocardiogram performed with the catheter tip in the proximal chamber showed an obstruction below the infundibulum and the appearances suggestive of anomalous muscle bundles. There was a translucent filling defect that ran obliquely downwards from right to left. It was crossed towards its right-hand end by a channel 7 to $8 \mathrm{~mm}$ wide that led into the infundibulum where there was post-stenotic dilatation. The recesses above the pulmonary valve cusps were deep. There was no shunt (Fig. 2a and b).

At operation the diagnosis was confirmed and hypertrophy of the bulbar muscle was observed. The pulmonary valve was normal. The obstructing muscle mass was excised; postoperative progress has been satisfactory.

\section{Case 2 (age 16 years)}

She was first seen at the age of 3 months because of a cardiac murmur and thought to have a small ventricular septal defect. She continued well and active, taking part in competitive sports and winning several medals for swimming. Her only complaint was that she could not compete with her sister who ran 400 metres for Wales.

On examination she was well built and a normal colour. A loud and long ejection systolic murmur was heard in the $4^{\text {th }}$ left intercostal space; the second sound was split and the pulmonary component was soft, suggesting infundibular pulmonary stenosis.

Her electrocardiogram showed a QRS frontal axis of $+80^{\circ}$ and no evidence of right ventricular enlargement. Chest radiographs showed no cardiac enlargement; the pulmonary artery was a little prominent but lung vascularity appeared normal (Fig. 3).

At cardiac catheterization, there was no demonstrable 


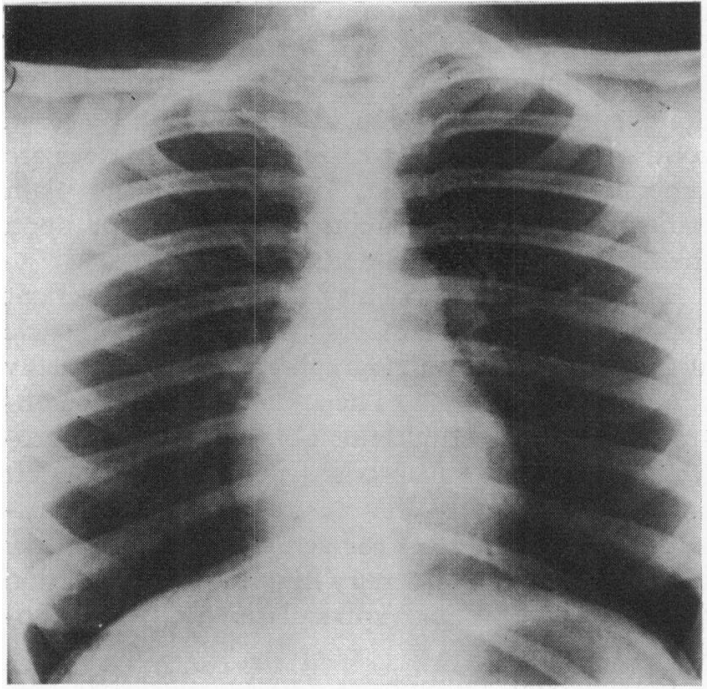

FI G. I $A$ chest radiograph showing a normal cardiac size and normal lung vascularity.

shunt. The main pulmonary artery was entered without difficulty and the withdrawal pressure trace showed a systolic gradient of $30 \mathrm{mmHg}$ at subinfundibular level. After a leg-raising exercise for 3 minutes, the systolic pressure gradient increased to $80 \mathrm{mmHg}$ - the systolic pressure in the proximal right ventricular chamber being I20 mmHg. A selective right ventricular angiogram showed obstruction well below the infundibulum. As in Case I, the obstruction produced a translucent filling defect that ran obliquely downwards from right to left, towards the apex (Fig. 4a and b).

At operation, hypertrophy of the bulbar muscle was found to obstruct the outflow of the right ventricle. The opening between the proximal and the distal chamber was about $\mathbf{I ~ c m}^{2}$ in size. The muscle bands were excised to relieve the obstruction and postoperative progress has been uneventful.

\section{Discussion}

Subinfundibular obstruction resulting in a twochambered right ventricle may not cause any significant symptoms (Forster and Humphries, I97I). The clinical findings suggestive of the diagnosis include a long and loud systolic murmur best heard in the 3rd and 4th left intercostal spaces, usually of ejection type. Pulmonary valve closure is frequently delayed and diminished in intensity. There is generally less clinical evidence of right ventricular hypertrophy than would be thought from the length of the systolic murmur.

The electrocardiogram shows certain characteristic features. Coats, McClenathan, and Scott (1964)

FI G. $2(a)$ and (b). Selective angiocardiograms in the right atrium showing the translucent filling defect in the right ventricle (arrows). $A$ jet of contrast can be seen traversing the subinfundibular obstruction.

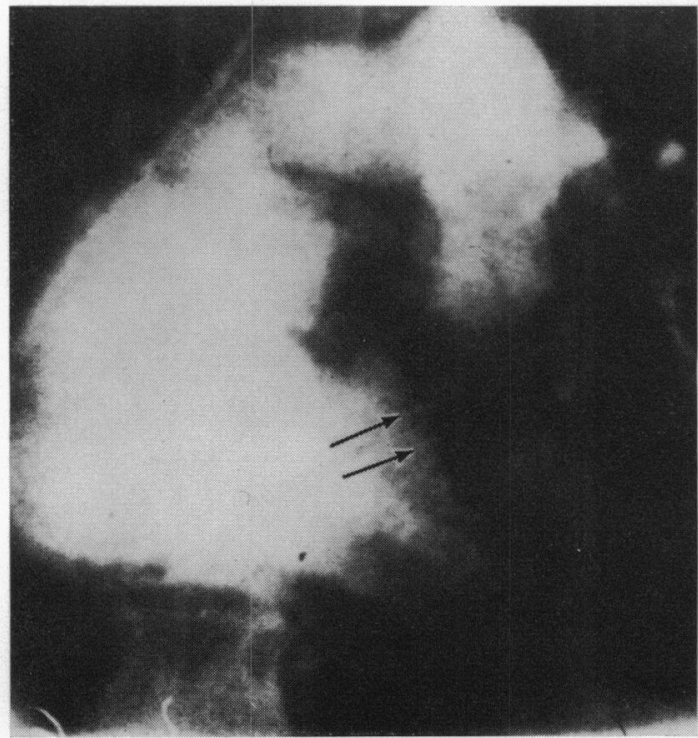

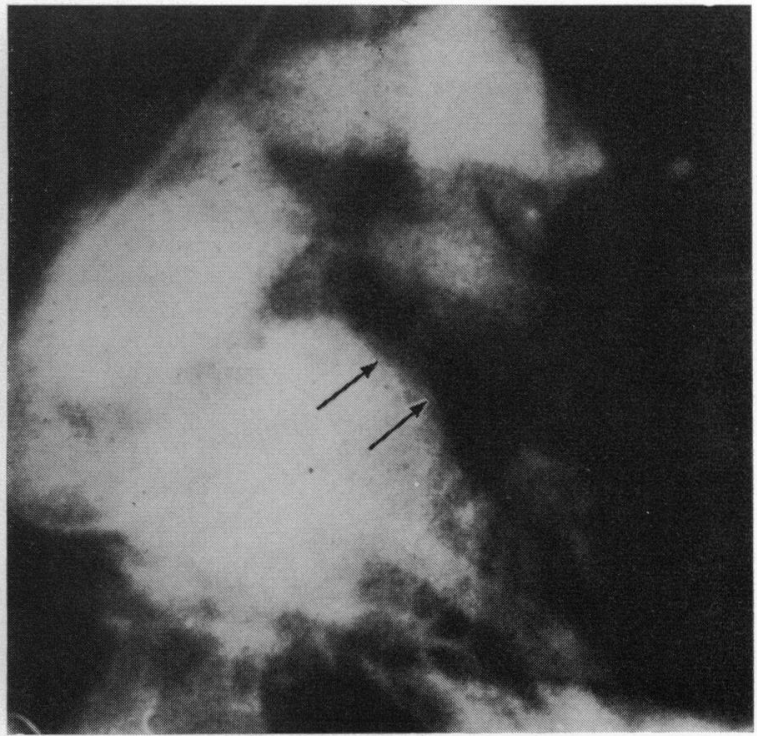




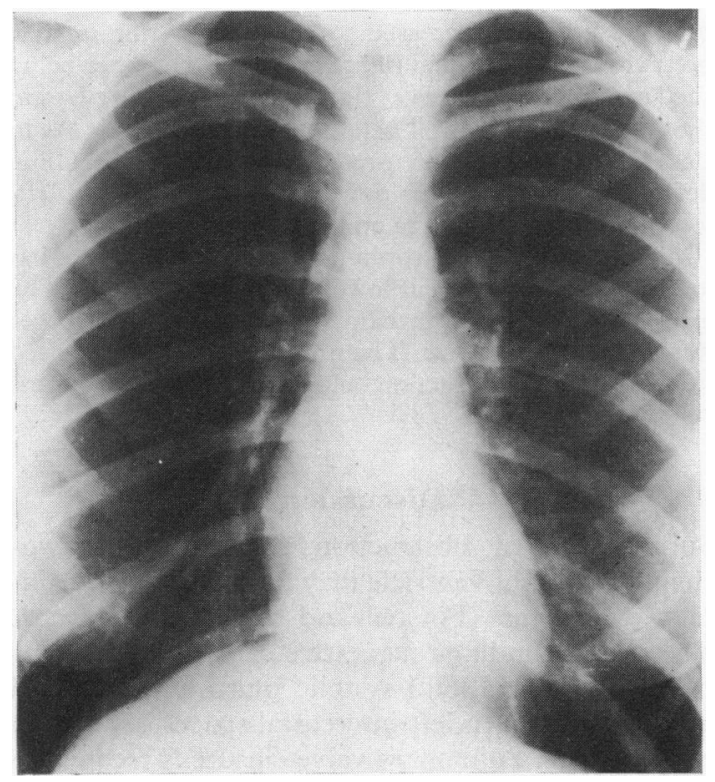

FI . $3 A$ chest radiograph showing a normal cardiac contour and normal lung vascularity. noted that it was common to find absence of positive QRS complexes in lead aVR, probably as a result of localized hypertrophy of the right ventricle. A dominant $R$ wave is frequently seen in lead $V_{4} R$ in contrast with a rS complex in lead VI. $S$ waves are generally absent in leads $V_{5}$ and V6. The plain radiographic findings are mainly dependent upon the degree of associated defects.

The demonstration of a systolic pressure gradient between the two chambers in the right ventricle along with a typical angiographic appearance usually confirms the diagnosis. The anomaly is best demonstrated in the right anterior oblique or frontal projection and is often obscured in the lateral or left anterior oblique view. There are one or more translucent bands that cross the ventricular cavity below the infundibulum generally in an oblique direction from the crista supraventricularis downwards towards the apex.

Forster and Humphries (197I) suggested that difficulty may be encountered in guiding the catheter from the right ventricle into the main pulmonary artery. They report two such cases where accidental perforation of the right ventricular outflow tract occurred. We did not encounter this difficulty in our cases. The proximal high pressure chamber can be

FIG. 4 (a) Selective angiocardiogram in the proximal chamber of the right ventricle demonstrating a translucent filling defect (arrows) in the subinfundibular region. (b) Selective angiogram in the distal chamber of the right ventricle showing the site of obstruction.
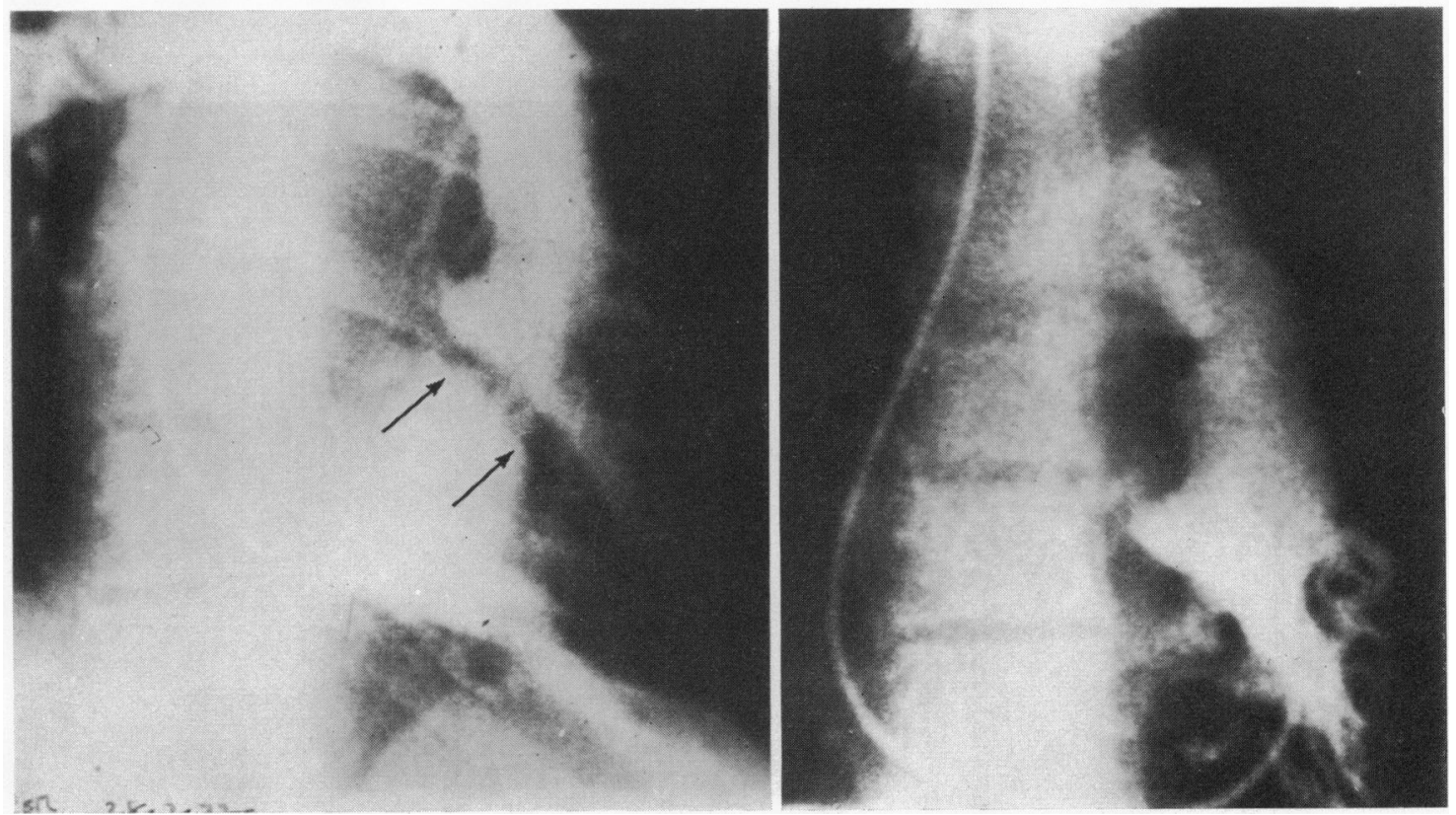
easily missed during a conventional withdrawal trace from the pulmonary artery to the right ventricle unless the pressure is also recorded in the apex of the right ventricle. It is also possible to be confused by the recording of a low pressure when the catheter tip lies at the cardiac apex; this occurs when the catheter has passed along the distal aspect of the obliquely directed anomalous bands as they slope downwards towards the apex.

Preoperative recognition of the defect is essential as an incorrect diagnosis has in the past led to shunt operations in 2 patients (Perloff, Ronan, and de Leon, 1965). Death occurred in a patient in whom the right ventricular obstruction was not recognized, and the orifice in the obstruction was thought to be a ventricular septal defect and closed (Lucas et al., 1962).

It is uncertain whether a double-chambered right ventricle can be regarded as a separate entity or whether it is a variant of infundibular obstruction that is unusually low. Perloff et al. (1965) consider that it is caused by aberrant bands of muscle. When there is a ventricular septal defect it may communicate either with the distal or the proximal chamber, a finding that supports the hypothesis of a separate embryological entity (Lucas et al., I962; Hartmann et al., 1962).

Recatheterization after several years in a few patients suggests that obstruction may be absent or minimal at first but then gets progressively worse (Hartmann, Goldring, and Carlsson, 1964). We believe that we have a patient at present with angio- graphic appearances of anomalous muscle bands in the right ventricle without any obstruction.

We are grateful to Dr. C. G. Parsons and Dr. S. P. Singh for allowing us to publish this report and to Mr. L. D. Abrams who performed the operations.

\section{References}

Coates, J. R., McClenathan, J. E., and Scott, L. P. (I964). The double-chambered right ventricle. A diagnostic and operative pitfall. American fournal of Cardiology, 14, 561.

Fisher, C. H., James, A. E., Humphries, J. O., Forster, J., and White, R. I. (1971). Radiographic findings in anomalous muscle bundle of the right ventricle. Radiology, Ior, 35.

Forster, J. W., and Humphries, J. O. (197I). Right ventricular anomalous muscle bundle; clinical and laboratory presentation and natural history. Circulation, 43, I I 5.

Gale, G. E., Heimann, K. W., and Barlow, J. B. (1969). Double-chambered right ventricle. British Heart fournal, 31, 291.

Hartmann, A. F., Jr., Goldring, D., and Carlsson, E. (1964). Development of right ventricular obstruction by aberrant muscular bands. Circulation, 30, 679.

Hartmann, A. F., Jr., Tsifutis, A. A., Arvidsson, H., and Goldring, D. (1962). The two-chambered right ventricle. Report of nine cases. Circulation, 26, 279.

Lucas, R. V., Jr., Varco, R. L., Lillehei, C. W., Adams, P., Anderson, R. C., and Edwards, J. E. (I962). Anomalous muscle bundle of the right ventricle. Hemodynamic consequences and surgical considerations. Circulation, 25, 443.

Perloff, J. K., Ronan, J. A., Jr., and de Leon, A. C. (I965). Ventricular septal defect with the 'two-chambered right ventricle'. American fournal of Cardiology, 16, 894.

Requests for reprints to Dr. R. Patel, The Children's Hospital, Ladywood Middleway, Birmingham Br6 8ET. 